\title{
Quality of life and parental styles assessed by adolescents suffering from inflammatory bowel diseases and their parents
}

This article was published in the following Dove Press journal:

Neuropsychiatric Disease and Treatment

23 March 2016

Number of times this article has been viewed

\author{
Daniela Jelenova' \\ Jan Prasko' \\ Marie Ociskova' \\ Klara Latalova' \\ Eva Karaskova ${ }^{2}$ \\ Radovan Hruby ${ }^{3}$ \\ Dana Kamaradova' \\ Vladimir Mihal ${ }^{2}$ \\ 'Department of Psychiatry, \\ ${ }^{2}$ Department of Pediatrics, Faculty \\ of Medicine and Dentistry, Palacký \\ University, University Hospital, \\ Olomouc, Czech Republic; ${ }^{3}$ Private \\ Practice, Martin, Slovak Republic
}

Correspondence: Jan Prasko Department of Psychiatry, Faculty of Medicine and Dentistry, Palacký University, University Hospital,

IP Pavlova 6, 77520 Olomouc,

Czech Republic

Tel +4206034l4930

Email praskojan@seznam.cz
Background: Inflammatory bowel diseases (IBDs) in adolescents are chronic medical conditions with a substantial influence on the quality of life (QoL) of the families.

Methods: A total of 27 adolescents suffering from IBD, 39 healthy adolescents, and their parents were included in the cross-sectional study. The adolescents completed the questionnaires ADOR (parenting styles), KidScreen-10 (QoL), SAD (The Scale of Anxiety in Children), and CDI (Children's Depression Inventory). The parents completed the BAI (Beck Anxiety Inventory), BDI-II (Beck Depression Inventory, second version), and PedsQL (Pediatrics Quality of Life) Family Impact Module.

Results: The parental styles of the parents of the IBD adolescents and controls were without significant differences. The only exception was that fathers' positive parental style was significantly higher in the fathers of the controls. There were no statistically significant differences between the IBD children and controls in the QoL assessed using KidScreen-10. However, the QoL of the parents of the ill children was significantly lower than that of the parents of the controls (PedsQL total scores in mothers $66.84 \pm 14.78$ vs $76.17 \pm 14.65$ and in fathers $68.86 \pm 16.35$ vs $81.74 \pm 12.89$, respectively). The mothers of the IBD adolescents were significantly more anxious (BAI scores $9.50 \pm 10.38$ vs $5.26 \pm 4.75$ ) and the fathers more depressed (BDI-II scores $7.23 \pm 6.50$ vs $3.64 \pm 3.51$ ) than the parents of the controls, but there was no difference in the levels of anxiety or depression between the IBD adolescents and the controls. The positive parental style of both the parents of the children suffering from IBD positively correlated with the QoL of the adolescents evaluated by KidScreen-10. The positive parental style of the fathers negatively correlated with the children's state and trait anxiety and negatively correlated with the severity of childhood depression.

Conclusion: The fathers of the IBD adolescents may exhibit low levels of positive parenting style and be mildly depressed, and the mothers tend to exhibit higher levels of anxiety.

Keywords: ulcerative colitis, Crohn's disease, parenting style, quality of life, anxiety, depression

\section{Introduction}

An inflammatory bowel disease (IBD) can adversely affect psychological adjustment and family interactions. The unpredictable nature of the disease can bring significant distress to the adolescents and their parents, and could influence the family atmosphere. $^{1,2}$

Adolescents' overall adjustment may depend on the IBD course, treatment, and longer-term effects (eg, growth and pubertal delay). In addition to the illness factors, issues such as cognitive capacity, the structuring of emotional regulation, and control 
of impulses can also affect the adolescents' adaptation to the disorder. In teenagers, when self-identity is unstable, coping with a disease such as IBD can be challenging. The teenagers may feel ashamed because of the poor body image due to weight gain induced by steroids or due to fecal incontinence. They can develop social anxiety because of absenteeism in school and loss of opportunities in social learning. Factors such as the patient's age; the amount of interference from the normal teenage activities, peers, and family support; and life stressors may impact the adolescents' response to IBD. ${ }^{2,3}$

Parents of IBD children may experience many stressors, such as financial claims, role changes, separations, and worries about the child's prognosis. Such experiences may influence well-being and increase hopelessness, depression, anxiety, or cause a sense of loss of control. ${ }^{1}$

The study of Knez et $\mathrm{al}^{4}$ showed that parents of adolescents suffering from IBD reported considerably decreased psychological health in comparison with the parents of healthy controls. A mutual association between chronic disease in adolescents and parental adaptation has been suggested. ${ }^{3,5}$

The members of families need to change many family rules and life style. Some parents spoke about not having enough time for the siblings of the patient and also had worries about the adverse impact of the disorder on the siblings. ${ }^{6}$ Parents usually struggle with nervousness, the burden of disease, and the existence of the family unit. ${ }^{6}$ Some studies also describe a harmful impact of a chronic illness of a child on the marital bond. ${ }^{7}$ Although both parents may display substantial anxiety and worries, only one parent (usually mother) is accepted as the main caregiver. The responsibility for maintaining health carefulness, observing illness status, administering medicines and treatments, in addition to caring for the family, has led to a phenomenon known as "carrying the burden" in mothers. ${ }^{8}$

In adolescence, parents encounter novel tasks, such as youths seeking independence. ${ }^{9}$ Investigation of child care and development found that careful nurture, liberty, and firm control result in higher levels of competence and social skills. ${ }^{10}$ Authoritarian parenting is a controlling, punishmentheavy parenting style in which parents make their children follow their commands with little or no explanation. ${ }^{11}$ However, authoritative parenting styles are often linked with higher levels of student achievement. ${ }^{12}$ Permissive parents try to be "friends" with their children; they use the approach of "no discipline" and have no behavioral expectation for the children. ${ }^{13}$ Liberal parenting is a style in which parents are very involved in the care but place few demands on children. ${ }^{11}$ Overparenting style defines parents who try to include themselves in every single part of a child's life, attempting to solve all problems and stifling the child's ability to act independently. ${ }^{13}$ In neglectful parenting, parents are uninvolved, dismissing the children's feelings, low in warmth and control, detached, undemanding, and low in responsiveness. ${ }^{13,14}$ Positive parenting is a style defined by constant support and leadership over developmental stages. $^{4}$

The aim of our study was to discover the parental style, occurrence of depression and anxiety in both the children with IBD and their parents, and its impact on the quality of life (QoL). The main hypothesis of the study was that parents of adolescents with IBD would show less positive parental style, mothers would display less autonomous and more directive parenting style and fathers would have less directive and more hostile style of parenting than parents of healthy controls. The second hypothesis was that less positive parenting style would be linked with worse QoL for both the parents and their offspring affected by IBD.

\section{Methods}

\section{Sample and ethics}

The patients were recruited in the years 2013-2014 from the Department of Pediatrics, University Hospital, Olomouc. The inclusion criteria were 13-16 years of age and the diagnosis of IBD stated, at least, 6 months prior to the beginning of the study. The diagnosis of IBD was established according to the ESPGHAN Revised Porto Criteria for the diagnosis of IBD in children and adolescents ${ }^{15}$ and according to the Czech guidelines for the diagnosis and management of pediatric IBD. Patients with a history of suspected IBD have to undergo all examinations: detailed physical examination, laboratory blood tests, endoscopic evaluation (esophagogastroduodenoscopy and ileocolonoscopy with histology), and imaging of the small bowel (usually magnetic resonance enterography).

The adolescents of the control healthy group were recruited from three different high school classes, and all students from those classes were asked to participate. The inclusion criteria for the control healthy group were the same age (13-16 years) and a declaration of not having any chronic illness or other medical issues. All subjects from both the IBD and control groups lived in similar conditions, with similar socioeconomic status; the level of education of parents was not monitored.

The participants were 29 adolescents with IBD and 42 healthy adolescents of the same age (13-16 years) and their parents. Patients were monitored for IBD; 19 patients were diagnosed with Crohn's disease and ten with ulcerative colitis. There were 15 boys and 14 girls in the study group. The disease 
activity in children with ulcerative colitis was assessed by the Pediatric Ulcerative Colitis Activity Index (PUCAI), a noninvasive, valid, highly reliable, and responsive index combining six items (abdominal pain, rectal bleeding, stool consistency, number of stools per 24 hours, nocturnal stools, and activity level). The PUCAI score ranges from 0 to 85 : a score of $<10$ denotes remission, 10-34 mild disease, 35-64 moderate disease, and 65-85 severe disease. The clinical activity of Crohn's disease was evaluated by the Pediatric Crohn's Disease Activity Index (PCDAI) combining subjective reporting, extraintestinal manifestations, physical examination findings, weight and height, and laboratory findings. The PCDAI score ranges from 0 to 100: a score of $\leq 10$ is consistent with remission, 11-30 indicates mild disease, and $\geq 30$ is a moderate-tosevere disease. ${ }^{24,25}$ Remission was defined as the PCDAI or PUCAI of less than ten points. According to the PUCAI and PCDAI, 25 children were in remission, and four presented low activity of disease at the time of the assessment. The research was conducted in accordance with the latest version of the Declaration of Helsinki. Written informed consents were acquired from all subjects, and the procedures were fully explained. The local Ethical Committee of University Hospital Olomouc approved this project.

\section{Assessment}

In this cross-sectional study, the adolescents completed the questionnaires ADOR (parenting styles assessed by adolescents), KidScreen-10 (QoL), SAD (The Scale of Anxiety in Children), and CDI (Children's Depression Inventory). The parents completed the BDI-II (Beck Depression Inventory, second version), BAI (Beck Anxiety Inventory), and PedsQL Family Impact Module. The psychologist administered the questionnaires. All questionnaires are self-report scales, and they were completed at home.

ADOR: ${ }^{16,17}$ This is a questionnaire measuring parental styles in which older children (13-18 years) assess the behavior of their mothers and fathers. The questionnaire provides information about how a child perceives parental styles and attitudes toward him/her by the mother and father. The questionnaire distinguishes positive, directive, hostile, autonomous, and desultory parental styles and calculates two indexes - positive/hostile and directive/autonomous. Rates range from "Never" to "Always" on a five-point scale. At the end of each subscale, the sum is divided by the number of questions in that subscale. The highest score indicates the participant's most frequently perceived parenting style.

KidScreen-10: It measures individual health and wellbeing of adolescents. ${ }^{18}$ It was developed as a self-report questionnaire appropriate for healthy and chronically ill children and teenagers. It includes ten items from the ten health-related QoL (HRQoL) dimensions: physical; psychological well-being; moods and emotions; self-perception; autonomy; parent relations and home life; social support and peers; school environment; social acceptance (bullying); and financial resources. Each question is rated on a fivepoint response scale. A higher score is indicative of a better HRQoL.

SAD: It measures the state anxiety and trait anxiety. This scale consists of two different subscales. In the first one, 20 questions measure the level of anxiety experienced at the moment; each question is rated on a three-point scale. The second 20 -item scale focuses on anxiety as a characteristic.

$\mathrm{CDI}:{ }^{19}$ This is a self-rating scale that measures depressive symptoms and is composed of 27 items that are grouped into five-factor areas, including negative mood, interpersonal problems, ineffectiveness, anhedonia, and negative self-esteem. High scores reflect more serious depressive symptomatology.

BDI-II: It is intended for assessing subjective depressive symptoms in adults. ${ }^{20}$ This self-rating scale with 21 depression indicators includes somatic and cognitiveaffective symptoms; each item is rated on a four-point scale. Scores of 16 or above indicate a possible depression.

BAI: It is a self-rating scale with 21 anxiety signs focusing primarily on physiological manifestations of anxiety in adults. The items are rated on a four-point scale; a total score of 16 or above indicates a possible anxiety disorder. ${ }^{20}$

PedsQL Family Impact Module: It is a parent-reported tool that assesses the effect of chronic pediatric disorders on the patient's HRQoL and their family functioning. ${ }^{21}$ This 36-item questionnaire for parents contains eight dimensions: physical functioning, emotional functioning, social functioning, cognitive functioning, communication, worry, daily activities, and family relationships. The Family Functioning Summary Score (PedsQL Fam) is computed from the eight items covering the areas of daily activities and family relationships, and the Parent Health-Related QoL Summary Score (PedsQL HRQoL) is computed from the 20 items covering areas of physical, emotional, social, and cognitive functioning scales. The questionnaire is designed to assess both parent self-reported functioning and parent-reported family functioning; in our study, we used only self-reported parental functioning. The children's version consists of 24 items in four dimensions (health related, feelings, relationships with peers, problems in school). The items are rated on a five-point Likert scale, and then linearly converted to a 0-100 scale. A higher score points to a better QoL. 


\section{Statistical analysis}

Demographic, clinical, and psychological data were examined using descriptive statistics. The Shapiro-Wilk $W$-test determined the normal distribution of the demographic and clinical data. Group differences between patients and their parents, and controls and their parents were examined using unpaired $t$-tests or the Mann-Whitney test in case of non-normal distribution of data. The chi-square test or Fisher's exact test was used for the analysis of categorical data. Pearson's correlation analysis calculated the relations between variables with normal distribution. Spearman's correlation analysis was used for data with non-normal distribution. GraphPad PRISM (version 5.0) was used for statistics. The level of significance was set at $P<0.05$.

\section{Results}

\section{Demographic and clinical characteristics}

The patient group consisted of 27 adolescents (out of 29, two did not complete questionnaires) with IBD, 22 mothers, and 19 fathers. In the control group, there were 39 (out of 42 , there were three dropouts, who did not complete the questionnaires) adolescents of the same age (13-16 years), 38 mothers, and 35 fathers. Seventeen patients were diagnosed with Crohn's disease and ten with ulcerative colitis (Table 1). The recommended diagnostic approach established the diagnosis. ${ }^{21}$ The treatment was based upon the current guidelines. ${ }^{22,23}$ The median duration of the treatment was 13 months (interquartile range 8-44 months). Sixteen patients with Crohn's disease and nine with ulcerative colitis were in clinical and laboratory remission of illness at the time of observation. Laboratory tests included C-reactive protein (CRP), thrombocytes, and hemoglobin.

As a control group, 72 children from three different high school classes were asked to participate in the study. A written consent was obtained from the parents of 42 children and completed questionnaires were returned by 39 children. The characteristics of the controls are presented in Table 1. Adolescents from the healthy control group declared they did not have any chronic illness or other medical issues.

\section{Comparison of adolescents with IBD, adolescents from the control group, and their parents}

The group of adolescents with IBD was comparable with the group of healthy controls regarding the age and sex distribution (Table 1).

The parental styles of the mothers and fathers of the IBD adolescents and the healthy controls were very similar, without statistically significant differences between the groups.
The only exception was the fathers' positive parental style, which was statistically significantly higher in the healthy children's parents (Table 1).

There were no differences between the IBD children and healthy controls in the QoL measured by KidScreen-10. Still, the parents' QoL rated by the mothers and fathers of the ill adolescents (PedsQL total scores) was significantly lower than in the control group, and the HRQoL (measured by PedsQL - HRQoL) in the fathers of the IBD children was lower than in the fathers of the healthy children (Table 1).

\section{Parental styles and their relations with QoL, depression, and anxiety}

Positive parental style

The positive parental style of the mothers of the children with IBD significantly correlated with the QoL of the children evaluated by KidScreen-10, but not correlated with other instruments (Table 2). The positive parenting style of the fathers of the children with IBD significantly correlated with the QoL of the children evaluated by KidScreen-10 and negatively correlated with current children anxiety (SAD state) and constant anxiety (SAD trait). The positive father parental style also highly significantly negatively correlated with the degree of depression in children measured by CDI (Table 2).

\section{Directive parental style}

The parental directive style of the mothers and fathers of children with IBD did not correlate with any measured factor (Table 2).

\section{Hostile parental style}

The hostile parental style of the mothers of the children with IBD highly negatively correlated with the quality of a child's life (measured by KidScreen-10) and child depression (measured by CDI) (Table 2). The hostile parental style of the fathers of the children with IBD also highly significantly negatively correlated with the quality of a child's life by KidScreen-10 and the total score of PedsQL, and positively with the anxiety of the child (both as a state and as a trait measured by $\mathrm{SAD}$ ) and with the level of child depression in CDI (Table 2).

\section{Autonomous parental style}

The autonomous parental style of the mothers of the children suffering from IBD positively correlated with the quality of a child's life by KidScreen-10 and negatively with the degree of child depression evaluated by CDI. The autonomous parental style in the fathers of the children with IBD correlated with no variable of interest (Table 2). 
Table I Comparison of adolescents with IBD and their parents with families of healthy controls

\begin{tabular}{|c|c|c|c|}
\hline & $\begin{array}{l}\text { IBD adolescents } \\
(n=27)\end{array}$ & $\begin{array}{l}\text { Healthy controls } \\
(n=39)\end{array}$ & Statistics \\
\hline Mean age, years & $\mid 5.1 \pm 1.20$ & $14.88 \pm 0.46$ & Mann-Whitney test: $M W U=356$ : ns \\
\hline Male/female & $14: 13$ & 29:10 & Fisher's exact test: ns \\
\hline \multicolumn{4}{|l|}{ Parenting style (ADOR) } \\
\hline ADOR mother positive & $17.09 \pm 3.96$ & $15.15 \pm 5.29$ & Unpaired $t$-test: $t=|.5||d f=6|: \mathrm{ns}$ \\
\hline ADOR mother directive & $12.59 \pm 4.39$ & $11.95 \pm 3.81$ & Unpaired $t$-test: $t=0.600 \mathrm{I} d f=60: \mathrm{ns}$ \\
\hline ADOR mother hostile & $5.23 \pm 4.81$ & $5.03 \pm 3.80$ & Unpaired $t$-test: $t=0.1823 \mathrm{df}=60: \mathrm{ns}$ \\
\hline ADOR mother autonomous & $11.00 \pm 3.84$ & $10.53 \pm 4.19$ & Unpaired $t$-test: $t=0.4397 \mathrm{df}=60: \mathrm{ns}$ \\
\hline ADOR mother desultory & $7.73 \pm 4.90$ & $8.19 \pm 3.96$ & Unpaired $t$-test: $t=0.3983 d f=58: \mathrm{ns}$ \\
\hline ADOR mother positive/hostile & $1 \mathrm{I} .86 \pm 7.88$ & $11.24 \pm 6.40$ & Unpaired $t$-test: $t=0.3357 \mathrm{df}=60: \mathrm{ns}$ \\
\hline ADOR mother directive/autonomous & $1.59 \pm 6.67$ & $1.43 \pm 6.42$ & Unpaired $t$-test: $t=0.09605 \mathrm{df}=60: \mathrm{ns}$ \\
\hline ADOR father positive & $12.32 \pm 6.6$ & $15.37 \pm 4.52$ & Unpaired $t$-test: $t=2.0$ I I df $=52: P<0.05$ \\
\hline ADOR father directive & $10.79 \pm 4.24$ & $11.13 \pm 3.86$ & Unpaired $t$-test: $t=0.3055 d f=55: \mathrm{ns}$ \\
\hline ADOR father hostile & $6.22 \pm 5.94$ & $4.81 \pm 3.49$ & Unpaired $t$-test $t=1.105 \mathrm{df}=52: \mathrm{ns}$ \\
\hline ADOR father autonomous & $11.16 \pm 5.19$ & $10.66 \pm 3.40$ & Unpaired $t$-test: $t=0.4367 \mathrm{df}=55: \mathrm{ns}$ \\
\hline ADOR father desultory & $7.63 \pm 5.17$ & $7.97 \pm 3.83$ & Unpaired $t$-test: $t=0.2798 d f=54: \mathrm{ns}$ \\
\hline ADOR father positive/hostile & $6.33 \pm 12.18$ & $10.5 \pm 6.45$ & Unpaired $t$-test: $t=1.619 \mathrm{df}=50: \mathrm{ns}$ \\
\hline ADOR father directive/autonomous & $-0.37 \pm 8.19$ & $0.47 \pm 5.47$ & Unpaired $t$-test: $t=0.4619 d f=55: \mathrm{ns}$ \\
\hline \multicolumn{4}{|l|}{ Quality of life } \\
\hline KidScreen-10 & $38.82 \pm 8.58$ & $38.24 \pm 4.76$ & Unpaired $t$-test: $t=0.2798 d f=54: \mathrm{ns}$ \\
\hline PedsQL total mother & $66.84 \pm 14.78$ & $76.17 \pm 14.65$ & Unpaired $t$-test: $t=2.154 \mathrm{df}=\mathbf{4 8 :} P<0.05$ \\
\hline PedsQL total father & $68.86 \pm 16.35$ & $81.74 \pm I 2.89$ & Unpaired $t$-test: $t=2.765 d f=38: P<0.01$ \\
\hline PedsQL Fam mother & $69.56 \pm 19.31$ & $77.94 \pm 16.59$ & Unpaired $t$-test $t=1.616 \mathrm{df}=48: \mathrm{ns}$ \\
\hline PedsQL Fam father & $7|.73 \pm| 7.4 \mid$ & $80.89 \pm 16.89$ & Unpaired $t$-test: $t=1.666 \mathrm{df}=38: \mathrm{ns}$ \\
\hline PedsQL HRQoL mother & $67.54 \pm 15.07$ & $74.11 \pm 15.30$ & Unpaired $t$-test: $t=1.464 \mathrm{df}=48: \mathrm{ns}$ \\
\hline PedsQL HRQoL father & $71.32 \pm 19.20$ & $82.02 \pm I 2.38$ & Unpaired $t$-test: $t=2.148 d f=38: P<0.05$ \\
\hline \multicolumn{4}{|l|}{ Anxiety } \\
\hline SAD state & $29.25 \pm 6.28$ & $29.59 \pm 4.31$ & Unpaired $t$-test: $t=0.2445 d f=57: \mathrm{ns}$ \\
\hline SAD trait & $32.75 \pm 9.49$ & $31.80 \pm 6.10$ & Unpaired $t$-test: $t=0.4708 d f=59: \mathrm{ns}$ \\
\hline BAI mothers & $9.50 \pm 10.39$ & $5.26 \pm 4.75$ & Unpaired $t$-test: $t=2.022 d f=50: P<0.05$ \\
\hline BAI fathers & $6.20 \pm 5.83$ & $4.44 \pm 4.87$ & Unpaired $t$-test: $t=1.028 d f=38: \mathrm{ns}$ \\
\hline \multicolumn{4}{|l|}{ Depression } \\
\hline CDI & $45.86 \pm 35.54$ & $38.76 \pm 28.53$ & Unpaired $t$-test $t=0.864 \mathrm{I} d f=6 \mathrm{I}: \mathrm{ns}$ \\
\hline BDI-II mothers & $9.56 \pm 8.69$ & $6.97 \pm 6.45$ & Unpaired $t$-test: $t=I .208 d f=49: \mathrm{ns}$ \\
\hline BDI-II fathers & $7.23 \pm 6.50$ & $3.64 \pm 3.51$ & Unpaired $t$-test: $t=2.299 d f=38: P<0.05$ \\
\hline
\end{tabular}

Notes: Data are presented as mean \pm standard deviation or ratio. Values in bold represent a statistically significant result.

Abbreviations: IBD, inflammatory bowel disease; ADOR, parental styles (positive, directive, hostile, autonomous, desultory, index positive/hostile, index directive/autonomous); PedsQL Fam, Family Functioning Summary Score; PedsQL HRQoL, Parent Health-Related Quality of Life Summary Score; PedsQL, Pediatrics Quality of Life; SAD, The Scale of Anxiety in Children; BAI, Beck Anxiety Inventory; CDI, Children's Depression Inventory; BDI-II, Beck Depression Inventory, second version; ns, not significant.

Table 2 Parental styles, depression, anxiety, and quality of life correlations in IBD families

\begin{tabular}{|c|c|c|c|c|c|c|c|c|c|c|}
\hline \multirow{2}{*}{$\begin{array}{l}\text { Parental styles } \\
\text { Measurements }\end{array}$} & \multicolumn{2}{|l|}{ Positive } & \multicolumn{2}{|c|}{ Directive } & \multicolumn{2}{|l|}{ Hostile } & \multicolumn{2}{|c|}{ Autonomous } & \multicolumn{2}{|c|}{ Desultory } \\
\hline & Mother & Father & Mother & Father & Mother & Father & Mother & Father & Mother & Father \\
\hline KidScreen-10 & $0.46 *$ & 0.76 *** & -0.22 & 0.14 & -0.70 *** & $-0.64 * *$ & $0.54 *$ & 0.16 & -0.37 & $-0.6 I^{* *}$ \\
\hline PedsQL child & 0.18 & $0.77^{* * *}$ & -0.08 & -0.11 & -0.44 & $-0.77 * * *$ & 0.31 & 0.40 & -0.37 & $-0.69 * *$ \\
\hline SAD state & -0.04 & $-0.5 I^{*}$ & 0.13 & 0.17 & 0.41 & $0.68^{* *}$ & -0.08 & -0.45 & 0.25 & 0.28 \\
\hline SAD trait & 0.06 & $-0.57^{*}$ & 0.25 & 0.27 & 0.38 & $0.77 * * *$ & -0.08 & -0.39 & 0.42 & $0.57^{*}$ \\
\hline BAI mothers & 0.08 & 0.05 & -0.45 & -0.16 & -0.12 & -0.02 & 0.40 & -0.03 & 0.16 & 0.06 \\
\hline BAI fathers & -0.03 & -0.04 & -0.09 & 0.00 & -0.01 & -0.03 & 0.16 & 0.06 & 0.32 & 0.27 \\
\hline CDI & -0.31 & $-0.75^{* * *}$ & 0.25 & 0.08 & $0.57 * *$ & $0.78 * * *$ & $-0.44^{*}$ & -0.44 & 0.32 & $0.69 * *$ \\
\hline BDI-II mothers & -0.07 & -0.28 & -0.23 & -0.20 & 0.11 & 0.22 & 0.11 & -0.15 & 0.36 & 0.24 \\
\hline BDI-II fathers & -0.07 & -0.17 & -0.19 & -0.29 & 0.04 & 0.04 & 0.37 & 0.11 & 0.21 & 0.07 \\
\hline PedsQL total mothers & -0.01 & 0.34 & 0.38 & -0.11 & 0.08 & -0.34 & 0.11 & 0.34 & -0.04 & -0.19 \\
\hline PedsQL total fathers & 0.08 & 0.16 & -0.26 & -0.28 & -0.33 & -0.35 & 0.06 & 0.02 & -0.28 & -0.28 \\
\hline
\end{tabular}

Notes: $* P<0.05 ; * * P<0.01 ; * * * p<0.001$.

Abbreviations: IBD, inflammatory bowel disease; PedsQL, Pediatrics Quality of Life; SAD, The Scale of Anxiety in Children; BAI, Beck Anxiety Inventory; CDI, Children's Depression Inventory; BDI-II, Beck Depression Inventory, second version. 


\section{Desultory parental style}

The inconsistent parental style of the mothers of the children with IBD did not correlate with measured variables. The inconsistent parental style of the fathers of the children with IBD correlated negatively with the quality of a child's life measured by KidScreen-10, with anxiety as a trait according to $\mathrm{SAD}$, and positively with the level of the child depression in CDI.

\section{Discussion QoL of adolescents and their parents}

The IBD adolescents and the controls displayed comparable levels of QoL. The results are unexpected because a significant number of studies described a lower QoL in the patients with IBD. ${ }^{1,26}$ Adolescents' overall adjustment may eventually vary based on influences such as the IBD course and treatment, and the present group was mostly in clinical remission.

There were significantly lower scores on the QoL of the parents of the adolescents with IBD than in the parents of the healthy controls. It seems that the parents of the chronically ill children with IBD restricted their lives because of the children's illness. This suggestion cannot be tested in our cross-sectional study. However, it is consistent with the suggestions of Jarret, ${ }^{5}$ Coffey, ${ }^{6}$ and Brown et al $^{3}$ in adolescents with chronic health conditions.

\section{Depression and anxiety in adolescents and their parents}

The parents of the IBD adolescents expressed a higher average level of anxiety (mothers) and depression (fathers) than the parents of the control group.

The fathers of the ill children reached higher mean scores of depression than the fathers of the control group, and this finding seems interesting despite the relative clinical insignificance of their mean scores. There were no statistically significant differences between the fathers with moderately high depression with scores greater than 16 in BDI. ${ }^{28}$ Van Oers et $\mathrm{a}^{29}$ also found higher scores of depression (but not anxiety) among the fathers of chronically ill children when compared to the fathers of healthy children.

The mean score of anxiety (measured by BAI) indicated moderate levels of anxiety in mothers of IBD adolescents, being at the border between normal scores of anxiety and clinically significant ones. ${ }^{27}$ However, there were only three mothers of IBD teenagers and one mother of healthy controls who reached scores higher than 18 , which is the cut point of the clinically relevant level of anxiety. The number of markedly anxious mothers was not statistically different between the groups.

Clearly, the mothers of the adolescents with IBD were more concerned and anxious than the mothers whose children did not suffer from a chronic health condition. Van Oers et $\mathrm{a}^{29}$ found higher scores of anxiety and depression in the mothers of chronically ill children. A similar finding of pervasive anxiety and worries in parents of chronically ill children was reported in a meta-synthesis by Coffey. ${ }^{6}$ These worries are more frequent among the mothers than the fathers of the ill children. ${ }^{6}$ Streisand et al ${ }^{30}$ directly connected the parental state anxiety and the parental stress stemming from the care of the chronically ill child. The tendency toward anxiety and the behavior related to it (vigilance), general emotional challenges, and the need for continual adjustment were also mentioned as common factors related to the parents' care for the child with juvenile chronic arthritis. ${ }^{31}$

\section{Correlations}

The QoL evaluated by the adolescents most positively correlated with the positive parenting styles of both parents and the autonomous style of mothers, and negatively correlated with the hostile parenting styles of both parents and the inconsistent parenting style of fathers. These findings are consistent with clinical practice and with several authors' conclusions about chronically ill adolescents. ${ }^{4,11,13,14}$

Maternal anxiety may further have a potentially negative impact on the family functioning (tendency to overparenting, low use of the autonomy parental style), the QoL of the parents and the children, and the quality of the dyadic relationship between the parents.

Van Oers et $\mathrm{a}^{29}$ stated that the most significant factors related to the anxiety and depression in mothers and the depression in fathers of ill children were problems encountered in daily life and stress related to parenting.

The tendency of the mothers to experience higher anxiety and the fathers' mild depression may lead to the parental styles common in the families with a chronically ill or physically challenged child - "the managing mother" and "the waiting father". ${ }^{31}$ The mother's overprotective and anxious parental style and the father's helpless one remaining in the background may influence the child's emotional state.

According to some studies, the relationship between the attachments and the illness is considered to be bidirectional. ${ }^{32-34}$ Patients with Crohn's disease exhibited a predominantly insecure attachment and perceived their parents' behaviors as characterized by low maternal care and high paternal overprotection..$^{32-34}$ 
It is interesting to note that the children's anxiety as a state as well as the anxiety as a trait significantly negatively correlated with the positive parental styles of the fathers, but not of the mothers (who were on average more anxious than the mothers of the controls), and was positively connected to the hostile parental style of the fathers, but not of the mothers. Additionally, anxiety as a trait positively correlated with the inconsistent parental style of the fathers, and not of the mothers.

The level of the children's depression negatively correlated with the positive parenting style of the fathers and not of the mothers. It also significantly positively correlated with the hostile parenting style of both parents and the inconsistent parenting style of the fathers, and negatively with the mothers' autonomous style.

\section{Limitations}

There are several limitations of the study that need to be stated. The most significant one is the small number of patients. Another limitation is the predominant use of the questionnaires based on self-evaluation. The use of these scales and questionnaires depends on the ability of introspection of the patients and their preparedness to be open and honest in the statements. Also, the clinical state of most of the patients was stabilized. These facts prevent the possibility of generalizing the results to the whole population of adolescents with IBD and their families. Other studies based on a larger population of patients with different stages of the disorder need to be carried out.

\section{Conclusion}

The fathers of the adolescents with IBD tend to show low levels of positive parenting and are mildly depressed. The mothers deal with higher levels of anxiety. The results suggest that the parents of the adolescents with IBD represent an important target group for psychosocial support to improve their QoL and overall mental state, as well as family functioning. Further research with a higher number of patients and focusing on patients and family needs would be beneficial.

\section{Acknowledgment}

This work was supported by IGA MZ CR NT 14281-3.

\section{Disclosure}

The authors report no conflicts of interest in this work.

\section{References}

1. Drell MJ, White TJH. Children's reaction to illness and hospitalization. In: Sadock BJ, Sadock VA, editors. Kaplan \& Sadock's Comprehensive Textbook of Psychiatry. 8th ed, vol II. Philadelphia, PA: Lippincott Williams \& Wilkins; 2005:3425-3434.
2. MacPhee M, Hoffenberg EJ, Feranchak A. Quality-of-life factors in adolescent inflammatory bowel disease. Inflamm Bowel Dis. 1998;4(1): $6-11$.

3. Brown RT, Wiener L, Kupst MJ, et al. Single parenting and children with chronic illness: an understudied phenomenon. J Pediatr Psychol. 2008; 33(4):408-421.

4. Knez R, Francisković T, Samarin RM, Niksić M. Parental quality of life in the framework of paediatric chronic gastrointestinal disease. Coll Antropol. 2011;35(Suppl 2):275-280.

5. Jarrett M. Parent's experience of coming to know the care of a chronically ill child. $J$ Adv Nurs. 1994;19:1050-1056.

6. Coffey JS. Parenting a child with chronic illness: a metasynthesis. Pediatr Nurs. 2006;32:51-59.

7. Youngblut JM, Brady NR, Brooten D, Thomas DJ. Factors influencing single mother's employment status. Health Care Women Int. 2000; $21: 125-136$

8. Hirose T, Ueda R. Long-term follow-up study of cerebral palsy children and coping behaviour of parents. $J$ Adv Nurs. 1990;15:762-770.

9. Berger SK. The Developing Person Through the Life Span. 8th ed. New York: Worth Publishers; 2011:273-278.

10. Spera C. A review of the relationship among parenting practices, parenting styles, and adolescent school achievement. Educ Psychol Rev. 2005;17(2):125-146.

11. Santrock JW. A Topical Approach to Life-Span Development. 3rd ed. New York: McGraw-Hill; 2007.

12. Rivers J, Mullis AK, Fortner LA, Mullis RL. Relationships between parenting styles and the academic performance of adolescents. J Fam Soc Work. 2012;15(3):202-216.

13. Morris AS, Cui L, Steinberg L. Parenting research and themes: what we have learned and where to go next. In: Larzelere RE, Morris AS, Harrist AW, editors. Authoritative Parenting: Synthesizing Nurturance and Discipline for Optimal Child Development. Washington, DC: American Psychological Association; 2013:35-58.

14. Alizadeh S, Abu Talib MB, Abdullah R, Mansor M. Relationship between parenting style and children's behavior problems. Asian Soc Sci. 2011;7(12):195-200.

15. Varni JW, Burwinkle TM, Dickinson P, et al. Evaluation of the built environment at a children's convalescent hospital: development of the Pediatric Quality of Life Inventory parent and staff satisfaction measures for pediatric health care facilities. J Dev Behav Pediatr. 2004; 25(1):10-20.

16. Matějček Z, Říčan P. ADOR. Dotaznik rodičovského jednání a postojů pro adolescenty. Príručka [The questionnaire of parental behavior and attitudes to adolescents]. Bratislava: Psychodiagnostika; 1983. Czech.

17. Robinson C, Mandleco B, Olsen SF, Hart CH. Authoritative, authoritarian, and permissive parenting practices: development of a new measure. Psychol Rep. 1995;77:819-830.

18. Ravens-Sieberer U, Gosch A, Rajmil L, et al. KIDSCREEN-52 qualityof-life measure for children and adolescents. Expert Rev Pharmacoecon Outcomes Res. 2005;5(3):353-364.

19. Kovacs M. Rating scales to assess depression in school-aged children. Acta Paedopsychiatr. 1981;46(5-6):305-315.

20. Beck AT, Steer RA, Carbin MG. Psychometric properties of the Beck Depression Inventory: twenty-five years of evaluation. Clin Psychol Rev. 1988;8(1):77-100.

21. Levine A, Koletzko S, Turner D, et al. ESPGHAN revised porto criteria for the diagnosis of inflammatory bowel disease in children and adolescents. J Pediatr Gastroenterol Nutr. 2014;58(6):795-806.

22. Ruemmele FM, Veres G, Kolho KL, et al; ECCO/ESPGHAN. Consensus guidelines of ECCO/ESPGHAN on the medical management of pediatric Crohn's disease. J Crohns Colitis. 2014;8(10): 1179-1207.

23. Turner D, Levine A, Escher JC, et al; European Crohn's and Colitis Organization; European Society for Paediatric Gastroenterology, Hepatology, and Nutrition. Management of pediatric ulcerative colitis: joint ECCO and ESPGHAN evidence-based consensus guidelines. J Pediatr Gastroenterol Nutr. 2012;55(3):340-361. 
24. Hyams JS, Ferry GD, Mandel FS, et al. Development and validation of a pediatric Crohn's disease activity index. J Pediatr Gastroenterol Nutr. 1991;12(4):439-447.

25. Turner D, Hyams J, Markowitz J, et al; Pediatric IBD Collaborative Research Group. Appraisal of the pediatric ulcerative colitis activity index (PUCAI). Inflamm Bowel Dis. 2009;15(8):1218-1223.

26. Cuntz U, Welt J, Ruppert E, Zillessen E. Determinanten der subjektiven Belastung durch chronisch-entzündliche Darmerkrankungen und ihre psychosozialen Folgen. Ergebnisse einer Studie bei 200 Patienten [Determination of subjective burden from chronic inflammatory bowel disease and its psychosocial consequences. Results from a study of 200 patients]. Psychother Psychosom Med Psychol. 1999;49:494-500. German.

27. JulianLJ.Measures of anxiety.Arthritis Care Res (Hoboken). 2011;63(S11): S467-S472.

28. Spreen O, Strauss E. A Compendium of Neuropsychological Tests. New York: Oxford University Press; 1991.

29. Van Oers HA, Haverman L, Limperg PF, van Dijk-Lokkart EM, Maurice-Stam H, Grootenhuis MA. Anxiety and depression in mothers and fathers of a chronically ill child. Matern Child Health J. 2014;18(8): 1993-2002.
30. Streisand R, Braniecki S, Tercyak KP, Kazak AE. Childhood illnessrelated parenting stress: the pediatric inventory for parents. J Pediatr Psychol. 2001;26(3):155-162.

31. Sallfors C, Hallberg LRM. A parental perspective on living with a chronically ill child: a qualitative study. Fam Syst Health. 2003;21(2): 193-204.

32. Agostini A, Rizzello F, Ravegnani G, et al. Adult attachment and early parental experiences in patients with Crohn's disease. Psychosomatics. 2010;51(3):208-215.

33. Agostini A, Rizzello F, Ravegnani G, et al. Parental bonding and inflammatory bowel disease. Psychosomatics. 2010;51(1):14-21.

34. Agostini A, Moretti M, Calabrese C, et al. Attachment and quality of life in patients with inflammatory bowel disease. Int J Colorectal Dis. 2014;29(10):1291-1296.

\section{Publish your work in this journal}

Neuropsychiatric Disease and Treatment is an international, peerreviewed journal of clinical therapeutics and pharmacology focusing on concise rapid reporting of clinical or pre-clinical studies on a range of neuropsychiatric and neurological disorders. This journal is indexed on PubMed Central, the 'PsycINFO' database and CAS, and is the official journal of The International Neuropsychiatric Association (INA). The manuscript management system is completely online and includes a very quick and fair peer-review system, which is all easy to use. Visit http://www.dovepress.com/testimonials.php to read real quotes from published authors. 